\title{
The spread of cholera in western Democratic Republic of the Congo is not unidirectional from East-West: a spatiotemporal analysis, 1973-2018
}

Harry César Ntumba Kayembe ${ }^{1,2,9^{*}}$, Catherine Linard ${ }^{3}$, Didier Bompangue ${ }^{1,4}$, Jérémie Muwonga ${ }^{5}$, Michel Moutschen ${ }^{6}$, Hippolyte Situakibanza ${ }^{7,8}$ and Pierre Ozer ${ }^{2}$

\begin{abstract}
Background: Cholera outbreaks in western Democratic Republic of the Congo (DRC) are thought to be primarily the result of westward spread of cases from the Great Lakes Region. However, other patterns of spatial spread in this part of the country should not be excluded. The aim of this study was to explore alternative routes of spatial spread in western DRC.

Methods: A literature review was conducted to reconstruct major outbreak expansions of cholera in western DRC since its introduction in 1973. We also collected data on cholera cases reported at the health zone (HZ) scale by the national surveillance system during 2000-2018. Based on data from routine disease surveillance, we identified two subperiods (week 45, 2012-week 42, 2013 and week 40, 2017-week 52, 2018) for which the retrospective space-time permutation scan statistic was implemented to detect spatiotemporal clusters of cholera cases and then to infer the spread patterns in western DRC other than that described in the literature.

Results: Beyond westward and cross-border spread in the West Congo Basin from the Great Lakes Region, other dynamics of cholera epidemic propagation were observed from neighboring countries, such as Angola, to nonendemic provinces of southwestern DRC. Space-time clustering analyses sequentially detected clusters of cholera cases from southwestern DRC to the northern provinces, demonstrating a downstream-to-upstream spread along the Congo River.

Conclusions: The spread of cholera in western DRC is not one-sided. There are other patterns of spatial spread, including a propagation from downstream to upstream areas along the Congo River, to be considered as preferential trajectories of cholera in western DRC.
\end{abstract}

Keywords: Cholera, Vibrio cholerae, Epidemic spread, Spatiotemporal analysis, Clusters, Democratic Republic of the Congo

*Correspondence: harry.kayembe@unikin.ac.cd

${ }^{9}$ Service d'Ecologie et Contrôle des Maladies Infectieuses, Département des Sciences de Base, Faculté de Médecine, Université de Kinshasa, Kin XI, B.P. : 834 , Kinshasa, Democratic Republic of the Congo

Full list of author information is available at the end of the article

\section{Background}

The seventh cholera pandemic (7P), which began in 1961 in the Sulawesi Archipelago (Indonesia), was introduced in Africa in the early 1970s. Since then, it was determined that cholera has been introduced several times into sub-Saharan Africa, causing large 
epidemics [1]. However, cholera affects the continent heterogeneously. Outbreaks are reported irregularly in most countries, while the disease occurs endemically with a strong annual seasonality in a handful of countries, including the Democratic Republic of the Congo (DRC) [2]. The latter is also one of the world's major areas of emergence and re-emergence of infectious diseases. Over the last decades, several important outbreaks were reported across the country, including Ebola Virus Disease [3], measles [4, 5], yellow fever [6], and Human African trypanosomiasis $[7,8]$.

Concerning cholera, the first traces of the disease in the DRC during the 7P were notified in 1973. The southwestern part of the country was affected through cases imported from neighboring Angola [9]. Five years later, cholera was imported from Tanzania to eastern DRC [9, 10], and then spread along the Great Lakes Region (GLR). The largest cholera epidemic occurred in this region, particularly in and around the city of Goma, in 1994 following the Rwandan Genocide and resulted in the deaths of over 50,000 refugees [11]. Between then and 2018, while considering that the 50,000 cholera cases threshold was also exceeded in 2017, the DRC reported over 571,800 cases and 20,900 deaths, accounting for $17 \%$ and $21 \%$ of African cholera-related morbidity and mortality, respectively [12]. Nevertheless, it should be noted that the proportion of households with access to improved drinking water sources increased from $46 \%$ in 2007 to $49 \%$ in 2013 and $59 \%$ in 2018. In rural areas, this proportion remained limited to less than $35 \%$ in 2018 , while it reached over $90 \%$ in urban areas. Access to improved sanitation facilities also remained low: only $33 \%$ of household (54\% in urban areas and $16 \%$ in rural areas) $[13,14]$.

Previous epidemiological and ecological studies have identified the lake areas in the GLR of eastern DRC as sources of cholera outbreaks and persistence of Vibrio cholerae [2, 15, 16]. From these hotspots, the disease propagates to surrounding areas not yet affected. Moreover, cholera intermittently spreads outside the GLR to main cities in the upstream eastern provinces, and then to downstream western provinces along the Congo River [17-19]. There are also reports of epidemics in some provinces along this axis after Rwandan refugees fled camps in eastern DRC during the second half of the 1990s [20-22]. This could indicate that the pattern of cholera spread in western DRC is mainly one-sided. However, the existence of other modes of propagation in this part of the country should not be excluded. It is therefore more than necessary to highlight the different dynamics of the spread of outbreaks in western DRC. This will allow the establishment of a permanent framework for collaboration between actors at the strategic and political levels aiming at anticipating and controlling them.
Here, the objectives were to summarize major outbreak expansions of cholera in western DRC documented since its introduction in 1973, and to explore alternative patterns of spatial spread in this part of the DRC.

\section{Methods \\ Study setting}

This study is focused on the western provinces of DRC which are located in the West Congo Basin. These provinces are among the 26 currently established since the promulgation of the Constitution in 2006 and made effective since 2015. Prior to this period, the DRC had a total of 11 provinces, of which Equateur, Bandundu, Kinshasa, and Bas-Congo (formerly Bas-Zaire) contained the current western provinces considered in this study (Fig. 1) [23].

The western DRC is considered to be affected by cholera outbreaks along the Congo River and then its tributaries. The Congo River generally flows west from Kisangani (Tshopo province), just below the falls, then gradually turns southwest, passing through Mbandaka (Equateur province), joining the Oubangi River, and rushing into the Malebo Pool. The cities of Kinshasa and Brazzaville (Republic of Congo) are located on the opposite banks of the Congo River at the Pool Malebo, where it narrows and forms a number of cataracts created by deep canyons. It then flows in the direction of Kongo Central province, towards Matadi and Boma, then empties into the Atlantic Ocean at the town of Moanda [24].

\section{Data collection}

\section{Information on major outbreak expansions of cholera} in western DRC documented since its introduction in 1973

We conducted a historical reconstruction of major outbreak expansions of cholera in western DRC since its introduction in 1973 using queries on PubMed, Google scholar, and Google. The following keywords were used: ("cholera" AND "Democratic Republic of the Congo"); ("cholera" AND "Central Africa"). We searched peerreviewed and non-peer-reviewed articles published in English or French and reports or disease outbreak news from humanitarian agencies focused on the period 19702018. Studies and reports or alerts addressing the disease dynamics in western DRC and neighboring countries in the West Congo Basin were included.

\section{Cholera data}

We obtained data on suspected cholera cases collected at the $\mathrm{HZ}$ level through the DRC Integrated Disease Surveillance and Response system (IDSRS) from January 2000 to December 2018. The World Health Organization (WHO) definition of a suspected cholera case is: "In areas where a cholera outbreak has not been 


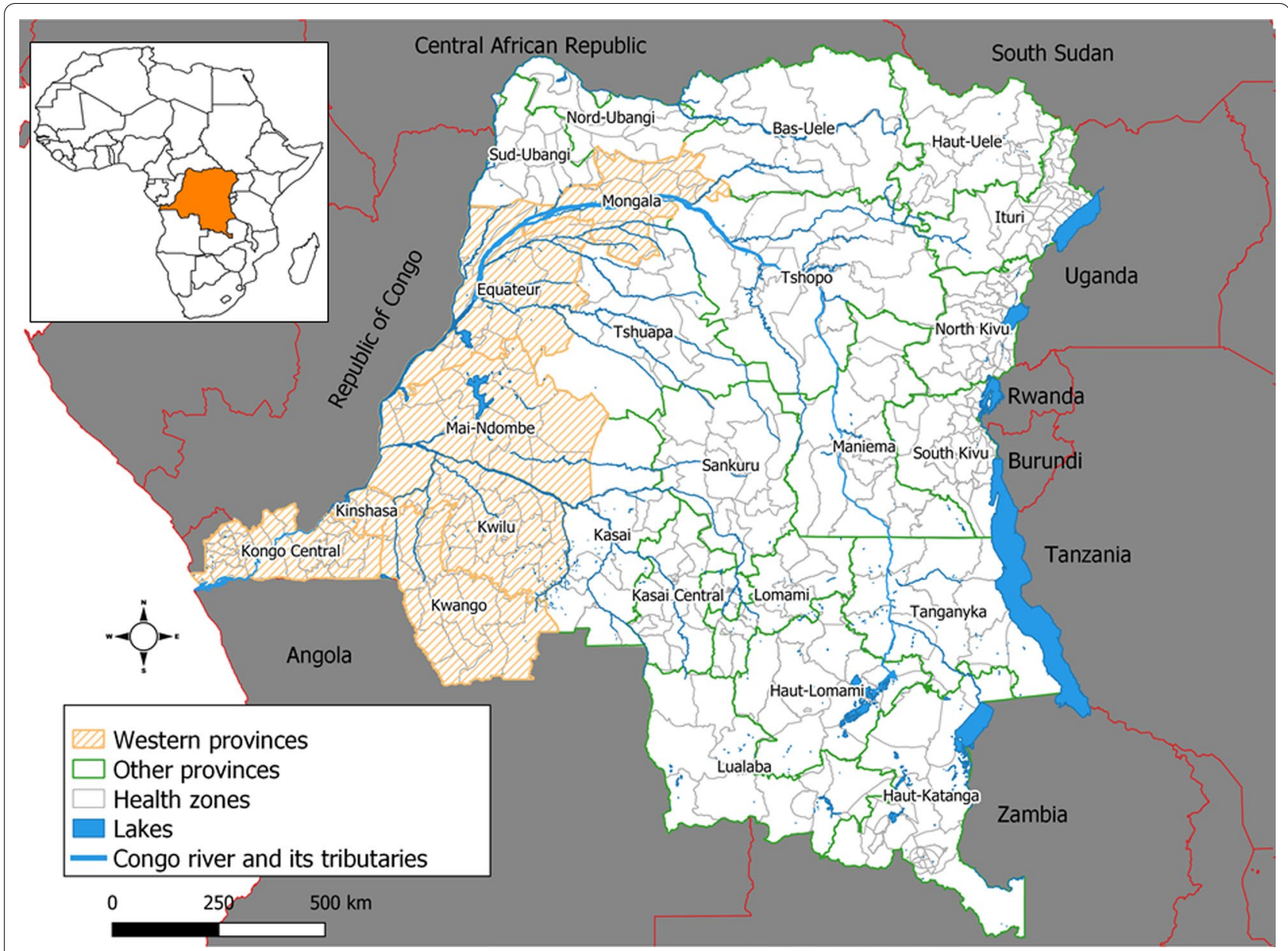

Fig. 1 Administrative map of the DRC

declared: Any patient aged 2 years and older presenting with acute watery diarrhea and severe dehydration or dying from acute watery diarrhea. In areas where a cholera outbreak is declared: any person presenting with or dying from acute watery diarrhea" [25]. Each new outbreak is confirmed by culture and isolation of Vibrio cholerae O1 from stool samples [26]. In the present study, cholera outbreaks were defined as the periods with the occurrence of at least one case over three consecutive weeks.

\section{GIS data}

Free open shapefiles of large-scale boundaries of African countries, on the one hand, and the DRC as well as Angola at subnational administrative level on the other hand, were obtained from the open access data platform "The Humanitarian Data Exchange" (https://data. humdata.org/).

\section{Data analysis}

We cross-referenced information from published articles, epidemiological reports, historical records, and news reports on cholera outbreaks to summarize the major outbreak expansions of the disease in western DRC since its introduction in 1973. Maps of routes of spread were developed using Quantum GIS version 3.8.3.

Based on recent cholera outbreaks that occurred in western DRC, we identified the subperiods to explore other spatial spread patterns than those described in the literature $[17,19]$. For each subperiod, we used the Kulldorff's retrospective space-time permutation scan statistic to detect spatiotemporal clusters of cholera cases using SaTScan software version 9.6 [27]. This model is used to assess which areas are most affected during a relatively short time interval (more or less a year) when the population does not change and to detect the cyclical trend of a disease or to explore 
unnoticed outbreaks. It requires only the number of cases, with information about the spatial location and time for each case. There is no need for information on the population at risk. Scan statistics are performed using a scanning window, defined as a cylinder with a circular or elliptic base, that moves through space and time, recording the number of observed and expected cases inside the window at each geographical location. Observed cases are compared to expected cases in a cluster if the geographical and temporal locations of all cases are independent of each other. Adjustments are automatically made for both purely spatial and purely temporal clusters. In our case, a cluster was detected in a $\mathrm{HZ}$ if, during a specific week, that $\mathrm{HZ}$ has a higher proportion of its cases compared to the remaining HZs. The most likely statistically significant cluster, whose window had the highest likelihood, was estimated for each random permutation by 999 Monte Carlo replications of the dataset simulated under the null hypothesis. As Horwood et al. [28], we set the maximum spatial window as a circle with a $125 \mathrm{~km}$ radius after identifying very large spatiotemporal clusters containing a number of statistically significant sub-clusters in preliminary analyses.

\section{Results}

We identified a list of 1751 records using the search terms. 208 records were deleted due to duplication and 1523 were excluded according to titles and abstracts or full texts that did not address the dynamics of the spread of cholera in western DRC and neighboring countries in the West Congo Basin. Only 19 studies and reports were considered relevant and detailed in Table 1.

The first epidemics to affect Kongo Central province (formerly Bas-Zaïre) in southwestern DRC were imported from Luanda, the capital of neighboring Angola, in 1973 and 1977 (number 1', Fig. 2) [9, 29, 30]. These epidemics originated from the wave that hit Angola in December 1971, most likely from the West African coast (number 1, Fig. 2) $[1,29,30]$. Genomic evidence suggests that the strains of Vibrio cholerae El Tor that invaded this part of the continent were introduced from South or East Asia to Russia and the Middle East [1].

Figure 2 also summarizes other dynamics of epidemic spread as follows: In 1997, the same Vibrio cholerae O1 sublineages were identified in Gabon (number 2') and southwestern DRC (Kinshasa; number 2) before being identified in Central African Republic (number 2") [31]; In 2006, from Luanda (February) to the inland province of Malanje in Angola (April), and then to the former Bandundu province in the DRC in July (number 3 ) [32, 33]; In 2006, from Cabinda province (Angola) to Kongo
Central, particularly in Kitona (19th week) and Moanda (28 ${ }^{\text {th }}$ week) (number 4) [32, 33]; In 2011-2012 and 20152017, from the Great Lakes Region to non-endemic provinces of western DRC (number 5) and then other countries in the West Congo Basin such as Republic of the Congo, Central African Republic (number 5") and Angola (particularly in the northern provinces bordering southwestern DRC; number 5') [17, 19, 32, 34-36]. Westward and cross-border spread in the West Congo Basin has been genetically confirmed $[1,31,37]$.

Figure 3 shows that there were a few small isolated peaks of epidemics in the early 2000s and in 2006, linked to the east-west dynamics initiated in previous years [31] and to cross-border spread from neighboring Angola [32], respectively. Recent cholera outbreaks in provinces of western DRC were reported during 2011-2018. Beyond the westward spread from cholera-endemic areas in the GLR and the recurrence of outbreaks with peaks one year apart described by Ingelbeen et al. in 2011-2012 and 2016-2017 [19], these provinces experienced a very low peak and substantial increases in suspected cholera cases after the first and second periods, respectively. Observed in both November 2012 and 2017 through the following year, it also appears that these outbreaks occurred first in the southwest and then in the upstream provinces.

Using SaTScan, the following spatiotemporal clusters were respectively identified during week 45 2012-week 422013 (Fig. 4): Kongo Central and western Kinshasa (week 45, 2012-week 4, 2013; cluster 1), eastern Kinshasa and Maï Ndombe (week 7-week 12, 2013; cluster 2), northern Maï Ndombe and southern Equateur (week 7-week 21, 2013; cluster 3), southern Mongala (week 9-week 10, 2013; cluster 4), and central Equateur (week 12-week 23, 2013; cluster 5). Clusters 6 and 7 were detected in southern Maï Ndombe-northern Kwilu (week 22-week 33, 2013) and Kongo Central (week 24week 42, 2013). See Additional file 1 for details of the clusters.

During week 40, 2017-week 52, 2018, spatiotemporal cluster analysis showed the following (Fig. 5): a first cluster detected in Kongo Central (week 40-week 51, 2017; cluster 1), followed by others identified in western Kinshasa (week 51, 2017-week 5, 2018; cluster 2), eastern Kinshasa and Maï Ndombe (week 3-week 15, 2018; cluster 4), northern Maï Ndombe and southern Equateur (week 7-week 21, 2018; cluster 5), Mongala (week 9week 10, 2018; cluster 6), and northern Equateur (week 42-week 44, 2018; cluster 9). The others were detected in Kongo Central (clusters 3 and 8) and the southern and northern parts of Maï Ndombe and Kwilu, respectively (cluster 7). See Additional file 2 for details of the clusters. 


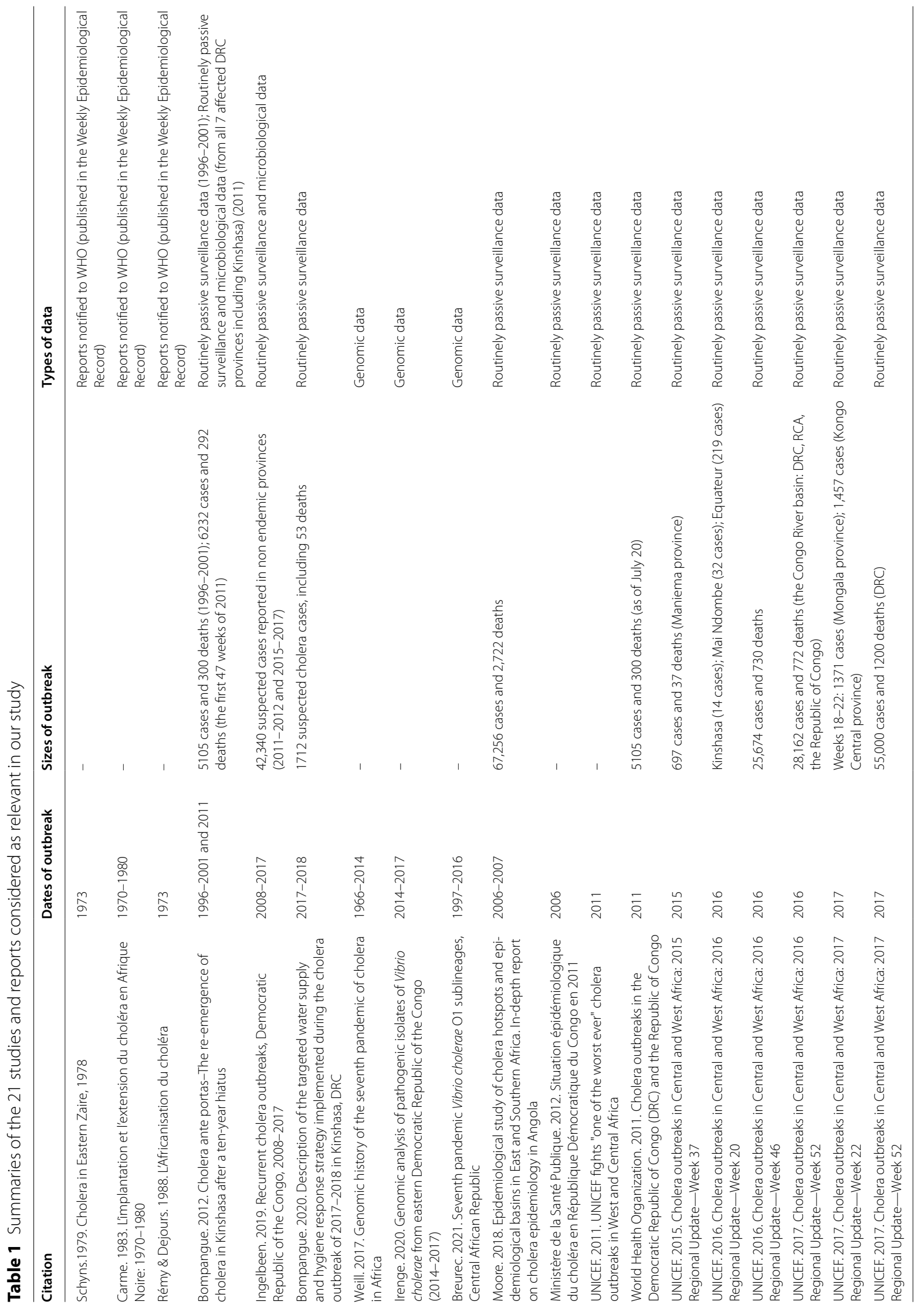




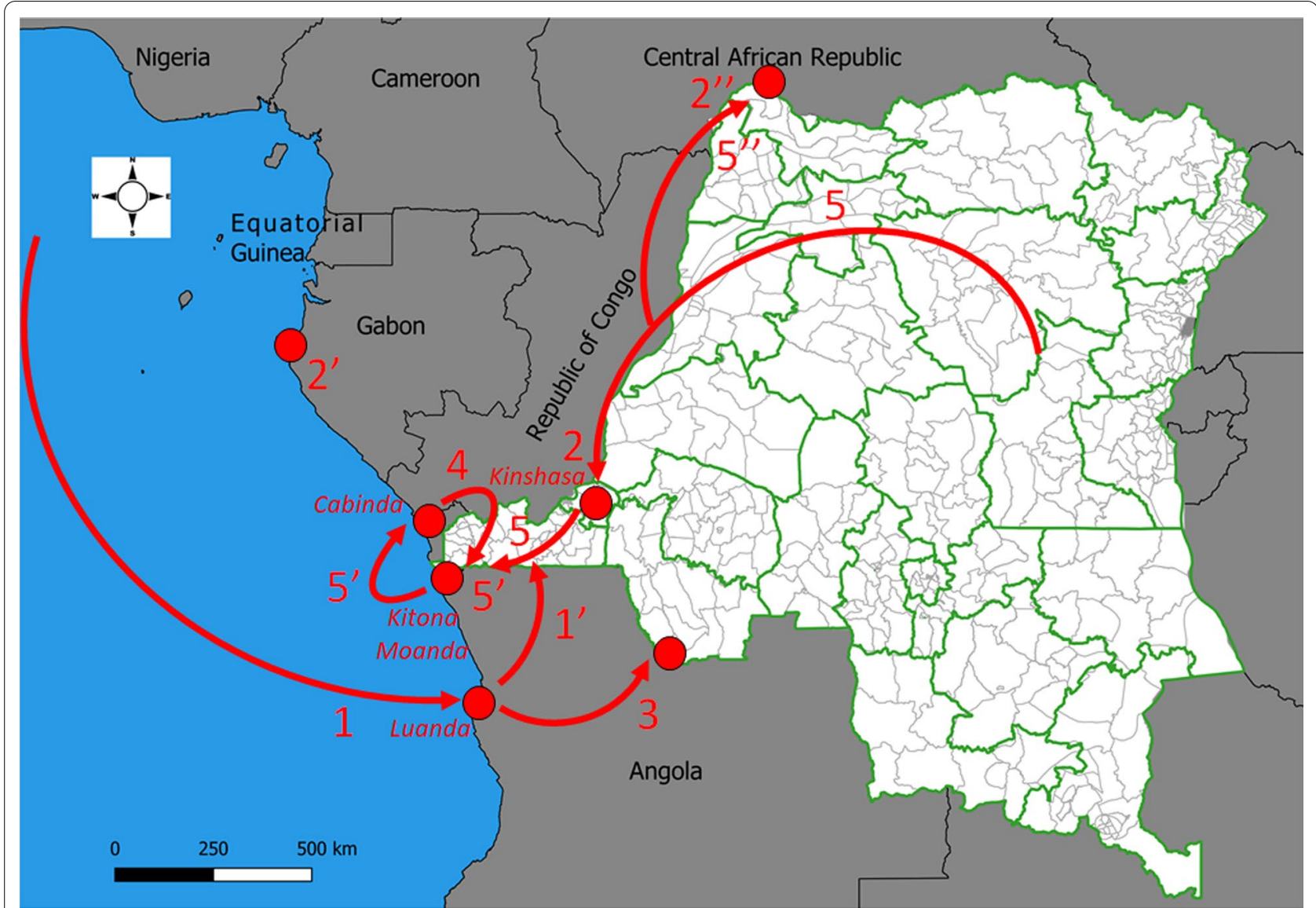

Fig. 2 Major outbreak expansions of cholera in western DRC documented since its introduction in 1973

\section{Discussion}

In this study, cross-referencing of published articles, epidemiological reports, historical records, and disease outbreak news of cholera revealed that beyond the spread of cholera from the GLR to western DRC increasingly documented to date [1, 17-19], outbreaks can be imported from neighboring countries into this part of the DRC. The westward spread of cholera is largely considered a significant risk factor of cross-border diffusion in the other countries of the West Congo Basin [1, 31, 37]. However, some cholera outbreaks that occurred in the provinces of southwestern DRC (Kongo Central, Kinshasa, and former Bandundu) were determined to be epidemiologically linked to outbreaks in the bordering northern provinces of Angola [9, 29, 30, 32, 33, 38].

Space-time permutation scan statistical analyses sequentially detected spatiotemporal clusters of cholera cases from southwestern to northwestern provinces in 2012-2013 and 2017-2018. This finding describes a downstream-to-upstream spread of cholera along the Congo River. As major rivers and roads are considered risk factors for cholera transmission $[15,39,40]$, substantial population movements across the border and the intensity of interactions at sites of mass gatherings along main roads in southwestern DRC, which is interconnected with upstream provinces via the Congo River, are likely to be associated with such spread dynamics. Note that frequent population movements across the border between the two countries were associated with similar cross-border transmission from Angola to southwestern DRC during the 2015-2016 yellow fever virus outbreak [41].

The results of the present study support the need for a permanent framework to promote cross-border collaboration between the countries within the West Congo Basin. In the field, information exchange and expertise sharing committees are set up in border areas during epidemics. However, these exchanges are infrequent, and even more non-existent in lull periods. The 


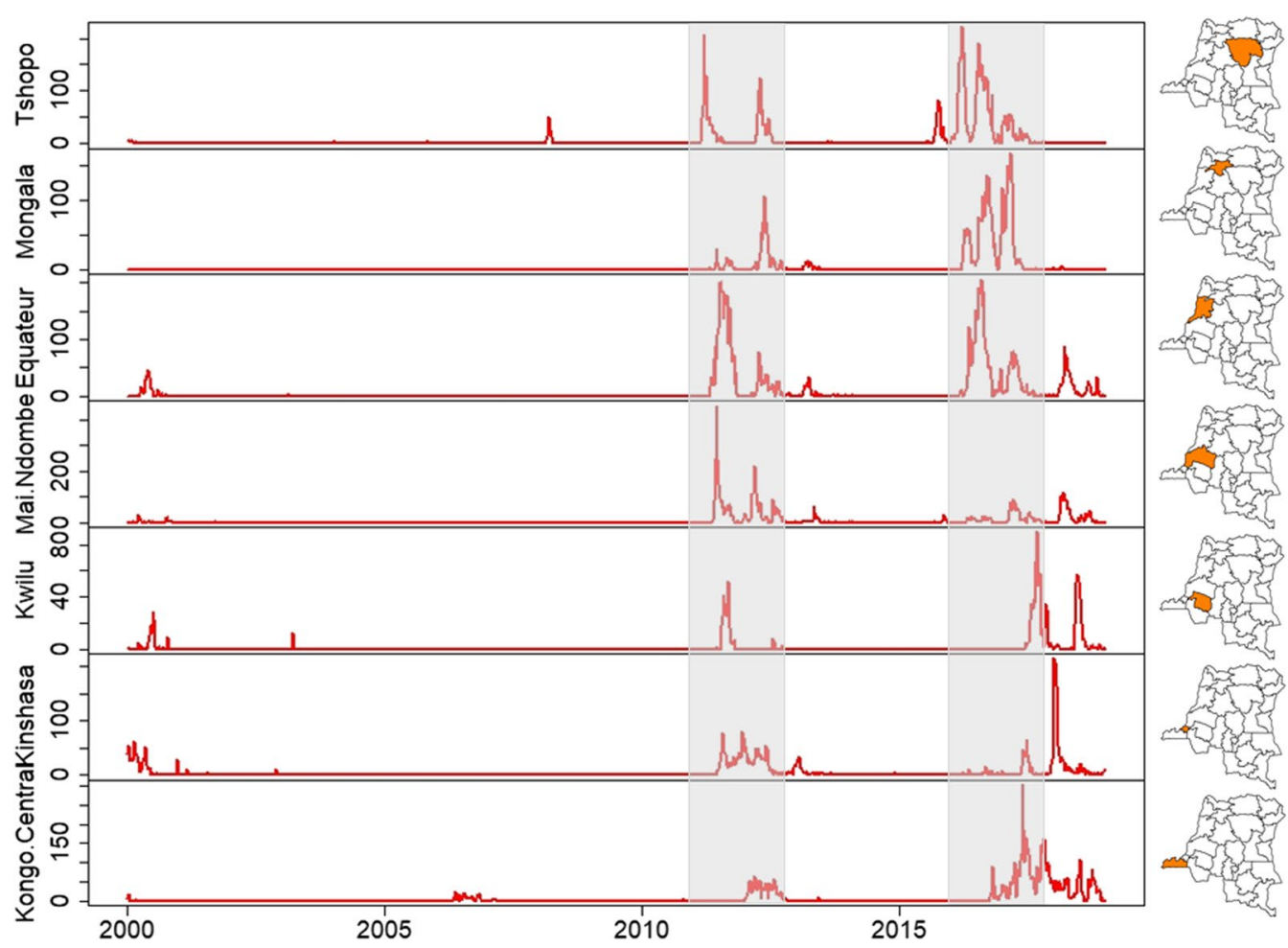

Fig. 3 Weekly notification of suspected cholera cases, western provinces of DRC, 2000-2018. From top to bottom: Tshopo, Mongala, Equateur, Maï Ndombe, Kwilu, Kinshasa, Kongo Central. Tshopo province has been included to highlight its non-involvement in the dynamics of cholera outbreaks in western DRC during the periods identified for the spatiotemporal cluster detection analysis. The grey rectangles correspond the periods 2011-2012 and 2016-2017

permanent framework for cross-border collaboration is therefore necessary to develop efficient policies and strategies that will allow coordination and implementation of multisectoral prevention and control interventions (previously prioritized); establishment of sustainable funding for cholera surveillance and outbreak emergencies; ensuring access to safe drinking water, sanitation and hygiene, as well as cholera vaccination, if recommended, for vulnerable populations; promoting community awareness of cholera and strengthen the knowledge and skills of local health-care providers [42]. It should be noted that community engagement is the key to successful implementation of interventions. Thus, taking into account local sociocultural sensibilities and practices depends on community-centered health education strategies carried by local stakeholders to build population confidence [43].

There are a number of limitations in this study. First, the use of data on suspected cholera cases. Confirmed cholera data would have smoothed out the probable over or underestimations of the number of cases reported. Also, genomic data from Vibrio cholerae O1 isolates would have described more definitive routes of cholera spread [1]. Nevertheless, a recent assessment on the level of adequacy of the weekly reported epidemic-prone diseases monitored by the DRC's surveillance system demonstrated that data on suspected cholera cases can be used for epidemiological research or public health purposes [44]. Moreover, another assessment of IDSR key performance indicators showed that the DRC figures among the African countries with high coverage of IDSR implementation at subnational level in terms of training, timeliness and completeness of reporting [45]. Second, the lack of cholera data from the national health information system prior to 2000 did not allow to find statistically significant transmission routes for the spread of cholera in western DRC during the corresponding period. However, this does not make the results of this study any less relevant. Our findings have the full merit of providing additional elements of understanding to the 


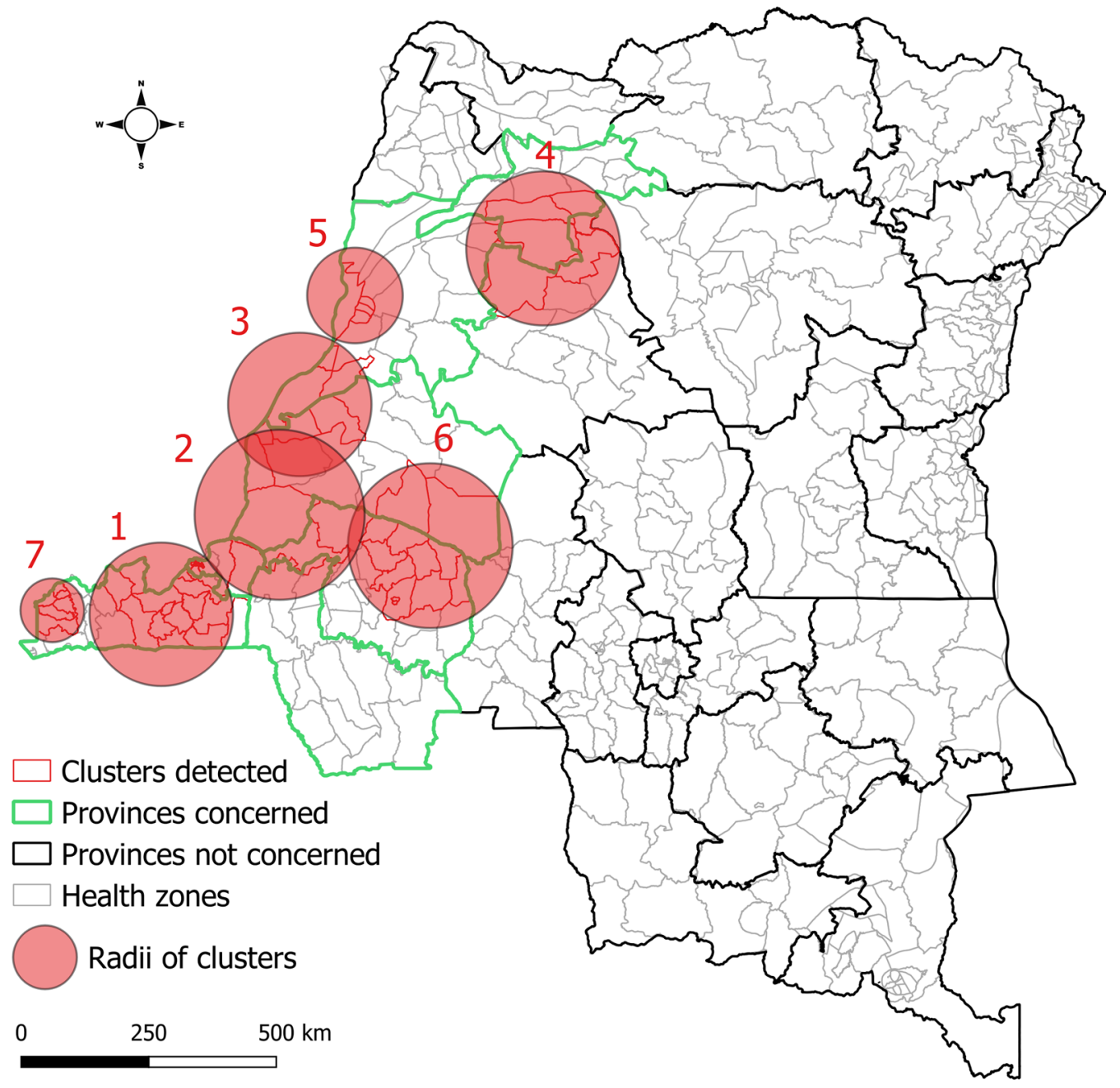

Fig. 4 Spatiotemporal clusters of cholera cases, western DRC, week 45, 2012-week 42, 2013

current state of knowledge on the spread dynamics of cholera in the DRC. Third, the space-time permutation scan statistic does not utilize information about a background population at risk. Although the overall population of the DRC has doubled over the past two decades [46], population data at the fine geographic scale, such as HZs, correspond to estimates based on a 1984 census with application of a calculated annual growth rate of $1.03 \%$ [47]. This poor quality of population data and the relatively short time interval corresponding to the two sub-periods identified to explore alternative patterns of spatial spread of cholera justify the use of the space-time permutation model.

\section{Conclusions}

The present study revealed that the spread of cholera in western DRC is not unidirectional from endemic areas in eastern DRC. Alternative patterns of spatial spread in this part of the country are effectively possible, in particular from downstream to upstream provinces along the Congo River. These patterns of spread should also be considered as preferential trajectories of cholera in the western provinces of the DRC. In addition, this study calls for policies and strategies that focus on cross-border collaboration between the countries in the West Congo Basin to achieve the goals of reducing cholera as a major public health concern by 2030 [48]. 


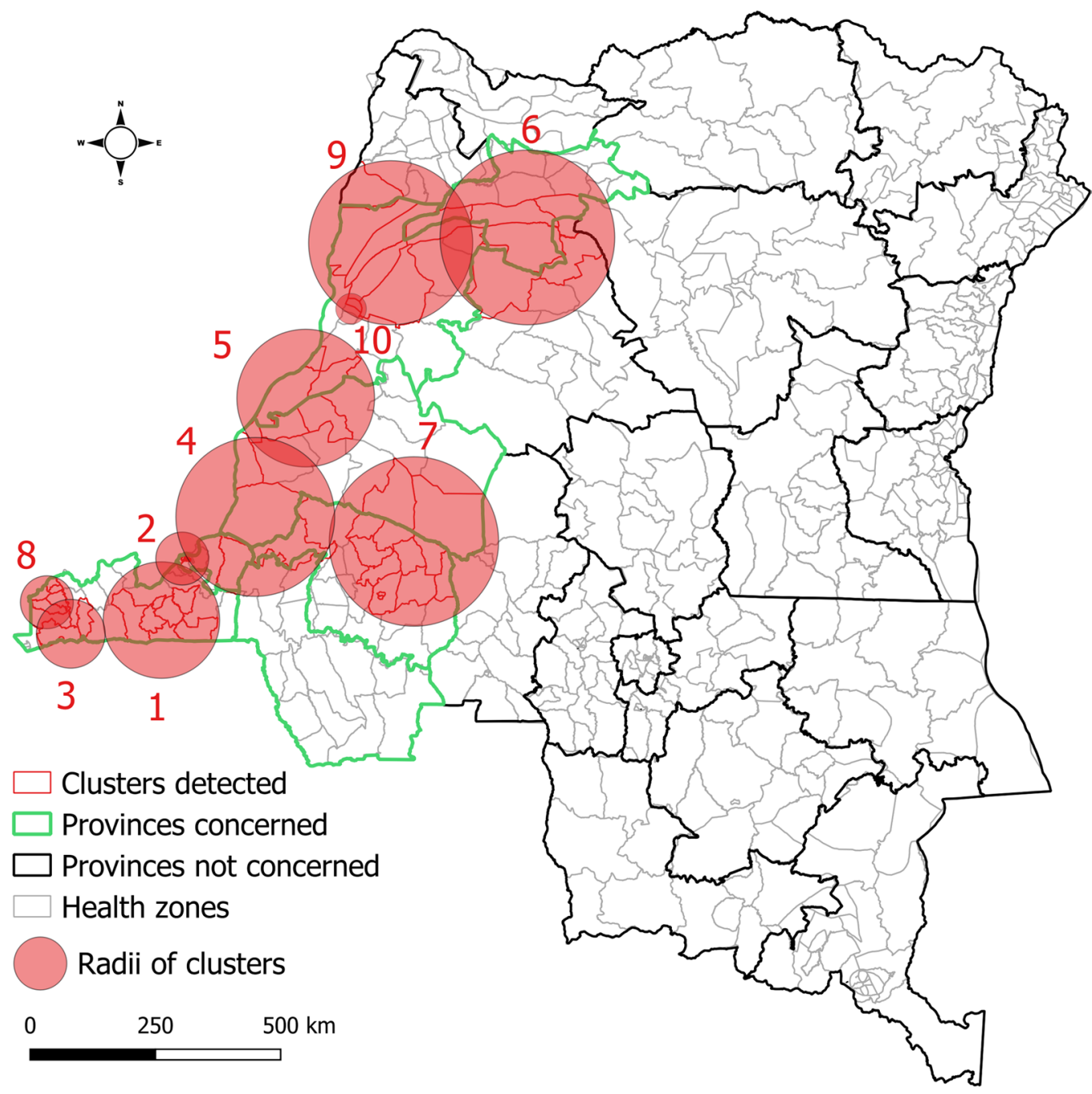

Fig. 5 Spatiotemporal clusters of cholera cases, western DRC, week 40, 2017-week 52, 2018

\section{Abbreviations}

7P: The seventh cholera pandemic; DRC: Democratic Republic of the Congo; GLR: Great Lakes Region; HZ: Health zone; IDSRS: Integrated Disease Surveillance and Response system; WHO: World Health Organization.

\section{Supplementary Information}

The online version contains supplementary material available at https://doi. org/10.1186/s12879-021-06986-9.

Additional file 1: Table S1. Detailed spatiotemporal clusters of cholera cases, western DRC, week 45, 2012-week 42, 2013.

Additional file 2: Table S2. Detailed spatiotemporal clusters of cholera cases, western DRC, week 40, 2017—week 52, 2018.

\section{Acknowledgements}

We are grateful to the Académie de Recherche et d'Enseignement Supérieur (ARES). We also thank Dr Bien-Aimé Mandja for his participation in the analysis and interpretation of the data, and all staff of the Research and Training Unit on Ecology and Control of Infectious Diseases [Unité de Recherche et de Formation en Écologie et Contrôle des Maladies Infectieuses (URF-ECMI)].

\section{Authors' contributions}

HCNK participated to the study design, data collection, data analysis and interpretation, and writing of the manuscript. CL participated to the study design, data interpretation and the reviewing of the manuscript. DB participated to the study design. JM participated to the study design. MM participated to the study design. HS participated to the study design, and the reviewing of the manuscript. PO participated to the study design, and the reviewing of the manuscript. All authors read and approved the final manuscript.

\section{Funding}

The present study did not receive financial support for publication.

\section{Availability of data and materials}

All data generated or analyzed during this study are included in this published article [and its additional information files].

\section{Declarations}

\section{Ethics approval and consent for participate}

This study was conducted in strict accordance with the ethical principles of the Declaration of Helsinki. We used routinely collected epidemiological 
surveillance data that are anonymized and aggregated at the $\mathrm{HZ}$ level. As human subjects were not involved, ethics approval was therefore not required.

\section{Consent for publication}

Not applicable.

\section{Competing interests}

The authors declare no competing interests.

\section{Author details}

'Service d'Ecologie et Contrôle des Maladies Infectieuses, Département des Sciences de Base, Faculté de Médecine, Université de Kinshasa, Kinshasa, Democratic Republic of the Congo. ${ }^{2}$ Département de Sciences Et Gestion de L'environnement, Faculté Des Sciences, Université de Liège, Arlon, Belgium. ${ }^{3}$ Département de Géographie, Université de Namur, Namur, Belgium. ${ }^{4}$ Chrono-Environnement, UMR CNRS 6249, Université de Franche-Comté, Besançon, France. ${ }^{5}$ Département de Biologie Clinique, Faculté de Médecine, Université de Kinshasa, Kinshasa, Democratic Republic of the Congo. ${ }^{6}$ Département des Sciences Cliniques, Immunopathologie-Maladies infectieuses et Médecine interne générale, Université de Liège, Liege, Belgium. ${ }^{7}$ Département de Médecine Interne, Faculté de Médecine, Université de Kinshasa, Kinshasa, Democratic Republic of the Congo. ${ }^{8}$ Département de Parasitologie Et Médecine Tropicale, Faculté de Médecine, Université de Kinshasa, Kinshasa, Democratic Republic of the Congo. ${ }^{9}$ Service d'Ecologie et Contrôle des Maladies Infectieuses, Département des Sciences de Base, Faculté de Médecine, Université de Kinshasa, Kin XI, B.P. : 834, Kinshasa, Democratic Republic of the Congo.

Received: 25 September 2021 Accepted: 16 December 2021 Published online: 19 December 2021

\section{References}

1. Weill F-X, Domman D, Njamkepo E, Tarr C, Rauzier J, Fawal N, et al. Genomic history of the seventh pandemic of cholera in Africa. Science. 2017;358(6364):785-9. https://science.sciencemag.org/content/358/ $6364 / 785$

2. Bompangue Nkoko D, Giraudoux P, Plisnier P-D, Tinda AM, Piarroux M, Sudre $B$, et al. Dynamics of cholera outbreaks in great lakes region of Africa, 1978-2008. Emerg Infect Dis. 2011;17(11):2026-34. https://hal. archives-ouvertes.fr/hal-00650525

3. Centers for Disease Control and Prevention. History of Ebola Virus Disease (EVD) Outbreaks. Cases and Outbreaks of EVD by Country. https://www. cdc.gov/vhf/ebola/history/chronology.html

4. Mancini S, Coldiron ME, Ronsse A, llunga BK, Porten K, Grais RF. Description of a large measles epidemic in Democratic Republic of Congo, 20102013. Confl Health. 2014;8(1):9. https://doi.org/10.1186/1752-1505-8-9.

5. Ducomble T, Gignoux E. Learning from a massive epidemic: measles in DRC. Lancet Infect Dis. 2020;20(5):542.

6. Ingelbeen B, Weregemere NA, Noel H, Tshapenda GP, Mossoko M, Nsio J, et al. Urban yellow fever outbreak-Democratic Republic of the Congo, 2016: Towards more rapid case detection. PLoS Negl Trop Dis. 2018;12(12):e0007029. https://doi.org/10.1371/journal.pntd.0007029.

7. World Health Organization. Control and surveillance of human African trypanosomiasis. World Health Organ Tech Rep Ser. 2013;984:1-237.

8. Lumbala C, Simarro PP, Cecchi G, Paone M, Franco JR, Mesu V, et al. Human African trypanosomiasis in the Democratic Republic of the Congo: disease distribution and risk. Int J Health Geogr. 2015;14:20.

9. Schyns C, Fossa A, et al. Cholera in Eastern Zaire, 1978. Ann Soc Belg Med Trop. 1979;59(4):391-400.

10. Malengreau M, Gillieaux M, De Feyter M, Wittman L. The cholera epidemic in Eastern Zaire in 1978. Ann Soc Belg Med Trop. 1979;59(4):401-12.

11. Goma Epidemiology Group. Public health impact of Rwandan refugee crisis: what happened in Goma, Zaire, in July, 1994? Lancet. 1995;345(8946):339-44.

12. World Health Organization. Cholera case and death numbers by country. Wkly Epidemiol Rec. http://www.who.int/cholera/en/

13. INS. Enquêtes par grappes à indicateurs multiples, 2017-2018, rapport des résultats de l'enquête. Kinshasa, République Démocratique du Congo. 2019. https://www.unicef.org/drcongo/rapports/ resume-mics-palu-2017-2018

14. Ministère du Plan et Suivi de la Mise en œuvre de la Révolution de la Modernité, Ministère de la Santé Publique et ICF International. Enquête Démographique et de Santé en République Démocratique du Congo. 2014. https://www.unicef.org/drcongo/media/1046/file/EDS-RDC\%20॥\% 202013-2014.pdf

15. Bompangue D, Giraudoux P, Handschumacher P, Piarroux M, Sudre B, Ekwanzala M, et al. Lakes as Source of Cholera Outbreaks, Democratic Republic of Congo. Emerg Infect Dis. 2008;14(5):798-800.

16. Bompangue D, Giraudoux P, Piarroux M, Mutombo G, Shamavu R, Sudre B, et al. Cholera Epidemics, War and Disasters around Goma and Lake Kivu: An Eight-Year Survey. PLoS Negl Trop Dis. 2009;3:5.

17. Bompangue D, Vesenbeckh SM, Giraudoux P, Castro M, Muyembe J-J, Ilunga BK, et al. Cholera ante portas-The re-emergence of cholera in Kinshasa after a ten-year hiatus. PLOS Curr Disasters. 2012;4:RRN1310. http:// currents.plos.org/disasters/article/cholera-ante-portas-the-re-emerg ence-of-cholera-in-kinshasa-after-a-ten-year-hiatus/

18. Rebaudet S, Sudre B, Faucher B, Piarroux R. Environmental determinants of cholera outbreaks in inland Africa: a systematic review of main transmission foci and propagation routes. J Infect Dis. 2013;208(Suppl 1):S46-54.

19. Ingelbeen B, Hendrickx D, Miwanda B, van der Sande MAB, Mossoko M, Vochten $\mathrm{H}$, et al. Recurrent Cholera Outbreaks, Democratic Republic of the Congo, 2008-2017. Emerg Infect Dis. 2019;25(5):856-64.

20. World Health Organization. 1997 - Health situation in Rwandan refugee camp in Zaire. 1997. https://www.who.int/csr/don/1997_01_20/en/

21. Centers for Disease Control and Prevention (CDC). Cholera outbreak among Rwandan refugees--Democratic Republic of Congo, April 1997. MMWR Morb Mortal Wkly Rep. 1998;47(19):389-91.

22. World Health Organization. Weekly epidemiological record - 18 April 1997. Wkly Epidemiol Rec. 1997;72(16):109-16.

23. Bruneau J-C. Les nouvelles provinces de la République Démocratique du Congo : construction territoriale et ethnicités [Internet]. L'Espace Politique. Revue en ligne de géographie politique et de géopolitique. Département de géographie de l'université de Reims ChampagneArdenne. 2009. https://journals.openedition.org/espacepolitique/1296

24. Neyt F. Fleuve Congo. Arts d'Afrique centrale, correspondances et mutations des formes. 2010. https://www.decitre.fr/livres/fleuve-congo-97890 61539148.html

25. GTFCC Surveillance Working Group. Interim guidance document on cholera surveillance. 2017. https://www.who.int/cholera/task_force/ GTFCC-Guidance-cholera-surveillance.pdf?ua=1

26. World Health Organization. Guidelines for Cholera Control. 1996. http:// helid.digicollection.org/en/d/Jwho90e/

27. Kulldorff M. SaTScanTM v9.6: Software for the Spatial and Space-Time Scan Statistics. Information Management Services. 2018. www.satscan. org.

28. Horwood PF, Karl S, Mueller I, Jonduo MH, Pavlin BI, Dagina R, et al. Spatio-temporal epidemiology of the cholera outbreak in Papua New Guinea, 2009-2011. BMC Infect Dis. 2014;14(1):449. https://doi.org/10. 1186/1471-2334-14-449.

29. Rémy G, Dejours H. L'Africanisation du choléra. Cahiers d'outre-mer. 1988;41(162):105-38. https://www.persee.fr/doc/caoum_0373-5834_ 1988_num_41_162_3258

30. Carme B, Mavumu Ngwak M, Trape J-F, Yala F, Felix M. L'implantation et l'extension du choléra en Afrique Noire : 1970-1980. Rev Méd Congo. 1983;2(34):17-29.

31. Breurec S, FranckT, Njamkepo E, Mbecko J-R, Rauzier J, Sanke-Waïgana H, et al. Seventh Pandemic Vibrio cholerae O1 Sublineages Central African Republic. Emerg Infect Dis. 2021;27(1):262-6.

32. Moore S, Dunoyer J, Sudre B, Valingot C, Rebaudet S, Piarroux R. Epidemiological study of cholera hotspots and epidemiological basins in East and Southern Africa. In-depth report on cholera epidemiology in Angola. UNICEF. 2018. http://www.platefor.mywhc.ca/attachments/article/794/ Cholera\%20epidemiology\%20in\%20Angola_UNICEF_2018_FINAL.pdf

33. Ministère de la Santé Publique. Situation épidémiologique du choléra en République Démocratique du Congo en 2011. 2012. https://reliefweb.int/ sites/reliefweb.int/files/resources/RAPPORT\%20SUR\%20LA\%20SITUATION\% 20DU\%20CHOLERA\%20EN\%20RDC\%20EN\%202011\%20DB-30_06_12.pdf 
34. UNICEF. UNICEF fights "one of the worst ever" cholera outbreaks in West and Central Africa - Cameroon. ReliefWeb. 2011. https://reliefweb.int/ report/cameroon/unicef-fights-\%E2\%80\%9Cone-worst-ever\%E2\%80\% 9D-cholera-outbreaks-west-and-central-africa

35. World Health Organization. Cholera outbreaks in the Democratic Republic of Congo (DRC) and the Republic of Congo [Internet]. WHO. World Health Organization; 2011 [cited 2021 May 12]. https://www.who.int/csr/ don/2011_07_22/en/

36. UNICEF. Cholera outbreaks in Central and West Africa: 2016 Regional Update - Week 52 [EN/FR] - Democratic Republic of the Congo. ReliefWeb. 2016. https://reliefweb.int/report/democratic-republic-congo/ cholera-outbreaks-central-and-west-africa-2016-regional-update-7

37. Irenge LM, Ambroise J, Mitangala PN, Bearzatto B, Kabangwa RKS, Durant $J-F$, et al. Genomic analysis of pathogenic isolates of Vibrio cholerae from eastern Democratic Republic of the Congo (2014-2017). PLoS Negl Trop Dis. 2020;14:4

38. World Health Organization. Global Task Force on Cholera Control - Cholera country profile: Angola. 2013. https://www.who.int/cholera/count ries/AngolaCountryProfile2013.pdf?ua $=1$

39. Ngwa MC, Liang S, Kracalik IT, Morris L, Blackburn JK, Mbam LM, et al. Cholera in Cameroon, 2000-2012: Spatial and Temporal Analysis at the Operational (Health District) and Sub Climate Levels. PLoS Negl Trop Dis. 2016;10(11):e0005105. https://doi.org/10.1371/journal.pntd.0005105.

40. Ngwa MC, Ihekweazu C, Okwor T, Yennan S, Williams N, Elimian K, et al. The cholera risk assessment in Kano State, Nigeria: A historical review, mapping of hotspots and evaluation of contextual factors. PLoS Negl Trop Dis. 2021;15(1):e0009046. https://doi.org/10.1371/journal.pntd. 0009046.

41. Kraemer MUG, Faria NR, Reiner RC, Golding N, Nikolay B, Stasse S, et al. Spread of yellow fever virus outbreak in Angola and the Democratic Republic of the Congo 2015-16: a modelling study. Lancet Infect Dis. 2017;17(3):330-8.

42. Pena ES, Bwire G, Dzotsi E, Bonnet MC, Hessel L. New momentum in prevention, control and elimination of cholera in Africa: priority actions identified by affected countries. Wkly Epidemiol Rec. 2016;91(24):305-16. https://www.who.int/wer/2016/wer9124.pdf?ua=1

43. Ntumba HCK, Bompangue D, Situakibanza H, Tamfum J-JM, Ozer P. Ebola response and community engagement: how to build a bridge? The Lancet. 2019;394(10216):2242. https://www.thelancet.com/journals/lancet/ article/PIIS0140-6736(19)32532-2/abstract

44. Mandja B-AM, Bompangue D, Handschumacher P, Gonzalez J-P, Salem $G$, Muyembe J-J, et al. The score of integrated disease surveillance and response adequacy (SIA): a pragmatic score for comparing weekly reported diseases based on a systematic review. BMC Public Health. 2019;19(1):624. https://doi.org/10.1186/s12889-019-6954-3

45. Fall IS, Rajatonirina S, Yahaya AA, Zabulon Y, Nsubuga P, Nanyunja M, et al. Integrated Disease Surveillance and Response (IDSR) strategy: current status, challenges and perspectives for the future in Africa. BMJ Glob Health. 2019;4(4):e001427. https://gh.bmj.com/content/4/4/e001427

46. The World Bank. Congo, Dem. Rep. | Data. https://data.worldbank.org/ country/CD

47. Mazamay S, Broutin H, Bompangue D, Muyembe J-J, Guégan J-F. The environmental drivers of bacterial meningitis epidemics in the Democratic Republic of Congo, central Africa. PLoS Negl Trop Dis. 2020;14(10):e0008634. https://doi.org/10.1371/journal.pntd.0008634.

48. Global Task Force on Cholera Control. Ending Cholera: A Global Roadmap to 2030. Geneva: World Health Organization. 2017. http://www.who.int/ cholera/publications/global-roadmap/en/

\section{Publisher's Note}

Springer Nature remains neutral with regard to jurisdictional claims in published maps and institutional affiliations.
Ready to submit your research? Choose BMC and benefit from:

- fast, convenient online submission

- thorough peer review by experienced researchers in your field

- rapid publication on acceptance

- support for research data, including large and complex data types

- gold Open Access which fosters wider collaboration and increased citations

- maximum visibility for your research: over $100 \mathrm{M}$ website views per year

At BMC, research is always in progress.

Learn more biomedcentral.com/submissions 